\title{
Analysis of mating system, fecundity, hatching and survival rates in two Schistosoma mansoni intermediate hosts (Biomphalaria pfeifferi and Biomphalaria camerunensis) in Cameroon
}

\author{
Alvine C. Kengne-Fokam¹, Hugues C. Nana-Djeunga ${ }^{1,2}$, Félicité F. Djuikwo-Teukeng ${ }^{3}$ and Flobert Njiokou ${ }^{1 *}$
}

\begin{abstract}
Background: Biomphalaria pfeifferi and Biomphalaria camerunensis are intermediate hosts of the trematode Schistosoma mansoni. Up till now, very scanty data report the life history traits of these freshwater snails. This study was therefore conducted to provide further knowledge on the mating system of these two $\mathrm{S}$. mansoni intermediate hosts in Cameroon. The study was performed following a three-step experimental design as follows: (i) for each species, a sample of young snails $\left(G_{1}\right)$, virgin and sexually mature was constituted and divided into two groups; (ii) in the first group, individuals were maintained isolated for the evaluation of the impact of self-fertilization on life history traits while in the second group, individuals were paired for few hours for the evaluation of cross-fertilization impact; (iii) in each group, fitness parameters (fecundity of $G_{1}$ snails and survival of $G_{2}$ offspring) were monitored during one month.

Results: The sexual maturity (age at first egg-laying) was reached, on average, at 63.9 (sd: 3.0) and 103.7 (sd: 36.6 ) days for B. pfeifferi and B. camerunensis, respectively. Copulation was observed in all paired individuals in both species. In B. pfeifferi, the fecundity (number of egg capsules and eggs) of young $G_{1}$ individuals and survival of $G_{2}$ offspring on $D_{0}$ and $\mathrm{D}_{8}$ were similar between selfing and outcrossing individuals, and a very low inbreeding depression (0.063) was observed. In B. camerunensis, the fecundity of outcrossed individuals was significantly higher than that of selfed individuals. The hatching rate was significantly higher and the incubation time significantly shorter for cross-fertilized eggs as compared with self-fertilized eggs, and a high inbreeding depression (0.71) was observed.

Conclusion: These findings may explain the high adaptability to more diverse and inconstant habitats, as well as the better compatibility of B. pfeifferi to S. mansoni compared with B. camerunensis, and may support the sustainability of $S$. mansoni life cycle where this intermediate host prevails.
\end{abstract}

Keywords: Mating system, Biomphalaria pfeifferi, Biomphalaria camerunensis, Life history traits, Inbreeding depression, Schistosoma mansoni

\footnotetext{
* Correspondence: njiokouf@yahoo.com

${ }^{1}$ University of Yaoundé 1, Parasitology and Ecology Laboratory, Faculty of

Science, PO Box 812, Yaoundé, Cameroon

Full list of author information is available at the end of the article
} 


\section{Background}

Hermaphrodism has been reported in 21 phyla of the Animal Kingdom, and self-fertilization is known in ascidians, cestodes, cnidarians, nematodes, trematodes, mollusks and vertebrates [1]. Fresh water pulmonate gastropods, especially basommatophorans, are the best studied group of mollusks [2-5]. Indeed, these snails represent an excellent model for mating system studies since (i) they are somehow easy to breed in the laboratory owing to their short life cycles (about 2-10 generations can be produced each year), and (ii) they are simultaneous hermaphrodites, thus able to reproduce through either self- or cross-fertilization $[3,6]$. Crossfertilization requires copulation during which one individual acts as a male while the other acts as a female. Female-acting fertilized individuals may store and use foreign sperm for several weeks after copulation without additional pairing [7], as has been previously reported in preferential outbred species such as Biomphalaria glabrata [8] or Bulinus globosus [9]. In the absence of mates, mature snails can either wait for the arrival of a hypothetical partner and pay for the cost of this delay (the increased risk of dying without reproducing), or self-fertilize their eggs and experience inbreeding depression [10, 11]. Inbreeding or self-fertilization depression refers to the relative reduction in fitness of inbred offspring as compared to outbred offspring, and may be used to study the mating system evolution among snail species [9, 11-13]. It was shown that preferential outcrossing species generally exhibit a high inbreeding depression [11] as has been observed in Lymnaea peregra [12], Physa acuta, Bulinus globosus, Biomphalaria glabrata [11] and Drepanotrema deprissimum [14]. However, self-crossing species such as Bulinus truncatus, Bulinus forskalii, and B. pfeifferi generally exhibit a low inbreeding depression [11].

The present study focuses on two gastropod species, B. pfeifferi and B. camerunensis that act as intermediate hosts of the trematode Schistosoma mansoni, and for which very few data regarding their life history traits are available. Both species are hermaphroditic fresh water snails, belonging to the Planorbidae family. $B$. pfeifferi dwells in a variety of more or less permanent water bodies including streams, irrigation channels and dam lakes [15-18]. Flooding and drought are responsible for the important fluctuations in population densities of this snail species, thus leading to bottlenecks and recolonization events $[12,18]$. As a consequence, limited neutral variability within populations and fairly large genetic differentiation among populations can be observed [17-19]. B. pfeifferi was described as a prior selfing species (selfing initiated prior to any outcrossing), very few copulations being observed in paired snails [20]. Genetic analyses at both family and population levels have indicated high selfing rates in B. pfeifferi $[18,21,22]$. Biomphalaria camerunensis species is distributed from Ghana eastwards to Central African Republic, and southwards to lower Democratic Republic of Congo (former Zaire) [16]. In Cameroon, B. camerunensis is confined to the southern equatorial climatic zone [23], and was never found in the same water collection with B. pfeifferi. It dwells in a variety of permanent waters including rivers, streams, lakes, swamps, and sometimes in temporary pools. B. camerunensis was considered as a preferential outbred species since population genetic studies have revealed heterozygote deficiency [24].

Despite these previous studies, an extensive knowledge of the mating systems of these two snail species may be helpful to master the transmission heterogeneity observed in intestinal schistosomiasis in Cameroon. In fact, B. pfeifferi is the main intermediate host of this trematode whereas $B$. camerunensis only plays a minor role in the transmission [16]. This knowledge can furthermore contribute to the development of strategies to control Schistosoma mansoni. Indeed, it was demonstrated that Biomphalaria tenagophila Taim lineage is highly resistant to $S$. mansoni, this innate defense system being a dominant character in cross-breedings with susceptible strains [25]. Thus, mastering the mating system of these intermediate hosts appears to be of prime importance in generating offspring resistant to the parasites after introduction of snail competitors [26]. To this end, a comprehensive study of the mating system of both Biomphalaria species was performed by monitoring the life history traits and evaluating the fitness parameters of isolated and paired snails under laboratory conditions.

\section{Methods}

Snail collection and rearing conditions

The two snail species included in this study were collected in two sites, both located in the Centre Region of Cameroon. A total of 28 wild B. camerunensis individuals were collected, in November 2012, in the Mounassi pond ( $4^{\circ} 12^{\prime} 14.1^{\prime \prime} \mathrm{N}$ and $11^{\circ} 35^{\prime} 00.2^{\prime \prime} \mathrm{E}$ ) in the Minkama III village (near Obala city). The water conductivity of the pond was 230 Siemens and its $\mathrm{pH}$ equal to 7.30. Also, 54 wild $B$. pfeifferi individuals were sampled, in March 2013, in a piscicultural lake in the Etokos quarter $\left(3^{\circ} 48^{\prime} 33.3^{\prime \prime} \mathrm{N}\right.$ and $\left.11^{\circ} 23^{\prime} 06.0^{\prime \prime} \mathrm{E}\right)$ located in the Yaoundé city. The conductivity and $\mathrm{pH}$ of the water of the lake were 162 Siemens and 7.12, respectively. All the snails collected were brought alive to the snail rearing room at the Faculty of Science of the University of Yaoundé 1, and maintained at $26 \pm 1{ }^{\circ} \mathrm{C}$ throughout the experiment, under a $12 \mathrm{~L} / 12 \mathrm{D}$ photoperiod. The conductivity of rearing water was 196 Siemens, and its $\mathrm{pH}$ equal to 6.96 . During the rearing, snails were fed ad libitum with dried lettuce. Water and lettuce were changed every day in rearing boxes containing very young snails, or every two 
days in those with juveniles and adults. Small floating pieces of polystyrene were introduced in the rearing boxes for egg capsules' laying.

\section{Experimental plan}

The experimental design of the present study is given as supplementary material [Additional file 1: Figure S1]. In the laboratory, wild snails $\left(G_{0}\right)$ from each species were kept together in a $1.5 \mathrm{~L}$ plastic box for acclimatization. Two days later, 15 mature individuals from each species were randomly chosen and isolated in $100 \mathrm{~mL}$ boxes. Two egg capsules were collected for each individual and incubated separately in $100 \mathrm{~mL}$ boxes. After hatching, juveniles of the first generation $\left(G_{1}\right)$ were maintained in rearing boxes for approximately three weeks. Three to four $G_{1}$ juveniles, aged 26 to 30 days (i.e. before sexual maturity) were chosen at random from each box, and a sample of $120 G_{1}$ snails constituted for each species. These $G_{1}$ individuals were isolated and reared until sexual maturity (first-egg-laying) was reached. The first individuals reaching sexual maturity were assigned to one of the two treatments, selfing $\left(\mathrm{T}_{1}\right)$ and outcrossing $\left(\mathrm{T}_{2}\right)$. Indeed, $40 \mathrm{~B}$. pfeifferi and $33 \mathrm{~B}$. camerunensis individuals were kept isolated throughout the experiment, and therefore self-fertilized $\left(\mathrm{T}_{1}\right) ; 40 \mathrm{~B}$. pfeifferi were paired together (20 couples) and 36 B. camerunensis were paired together (18 couples) during three successive days (see more details below) after which they were isolated again $\left(\mathrm{T}_{2}\right)$. After the three days of copulation, two egg capsules were collected for each snail from each treatment for the estimation of hatching and survival (over a month) rates for individuals of the second generation $\left(G_{2}\right)$.

\section{Assessment of life-history traits}

For each individual snail, the age at sexual maturity (age at first egg-laying) was recorded, and the numbers of egg capsules as well as eggs laid over 30 days, according to the type of treatment, were counted using a binocular magnifying glass. After the three days of pairing, one capsule was collected per snail to estimate the juvenile survival rate. To do this, the number of living embryos, the incubation time (estimated in days), the number of hatching individuals (from the first day of survival, that is on $D_{0}$ ), as well as the number of juveniles surviving at $8\left(D_{8}\right), 16\left(D_{16}\right)$ and $30\left(D_{30}\right)$ days after hatching were recorded. Inbreeding depression was calculated in each group using the following formula:

$$
\mathrm{d}=1-(\mathrm{Ws} / \mathrm{Wc}) \text {, where } \mathrm{W}=\mathrm{v}^{*} \mathrm{f}
$$

In this formula, $W_{s}$ and $W_{c}$ stand for the selective value in self-fertilization and cross-fertilization, respectively; $\mathrm{v}$ is the hatching rate or the viability of $\mathrm{G}_{2}$ snails over 30 days, and $\mathrm{f}$ the mean number of eggs laid by $\mathrm{G}_{1}$ snails over 30 days. The inbreeding depression was assessed using an easy-to-use indirect method as previously demonstrated in other Basommathophorans [11] and in plants [27]. Its estimation was possible since cross-fertilization was demonstrated in paired B. pfeifferi individuals [28]. Since inbreeding depression is usually larger at the earlier stage of the life cycle, apparent inbreeding depression, taking into account only hatching and early survival of juveniles, was computed [29].

\section{Statistical analyses}

Statistical analyses were performed using the software PASW Statistics 18 (SPSS Inc., Chicago, IL, USA). A normality test was first performed to assess the distribution of each quantitative parameter. Then, the mean number of egg capsules, eggs per capsule laid, copulation and average copulation duration were compared between isolated and paired individuals using the parametric Student t-test, and the number of hatched eggs as well as the incubation time between the two groups were compared using the non-parametric Man Whitney test. The hatchability (evaluated on Day 0 ) and survival of the offspring (assessed on $\mathrm{D}_{8}, \mathrm{D}_{16}$ and $\mathrm{D}_{30}$ ) were compared using the Chi-square test.

\section{Results}

\section{Age at sexual maturity}

Sexual maturity was reached between 59 and 71 days (mean: 63.9; standard deviation (sd): 3.0), and between 60 and 175 days (mean: 103.7; sd: 36.6) for B. pfeifferi and $B$. camerunensis, respectively. The age at sexual maturity was reached earlier for $B$. pfeifferi individuals as compared to B. camerunensis individuals $(p<0.005)$.

\section{Selfing estimates}

All B. pfeifferi isolated individuals survived and laid egg capsules during the 32 weeks of the performance of the experiment. However, among the 119 B. camerunensis isolated individuals, $17(14.3 \%)$ died within the 32 weeks of the performance of the experiment, $69(58.0 \%)$ laid at least one egg capsule during this period, whereas 33 $(27.7 \%)$ never laid any egg capsule. The number of egg capsules laid was similar between the two snail species $(p=0.95)$, whereas the mean number of eggs was higher in $B$. pfeifferi than in B. camerunensis individuals $(p<0.0001)$ (Table 1). Although the incubation time was similar between the two species, the hatching rate was significantly higher in B. pfeifferi, and survival of $\mathrm{G}_{2}$ individuals was higher in B. camerunensis (Table 1).

\section{Copulation metrics}

Copulations were observed in all 17 pairs of virgin $B$. pfeifferi individuals and in 15 pairs of virgin $B$. 
Table 1 Fecundity and survival estimates for isolated (T1) and paired (T2) individuals from Biomphalaria pfeifferi and Biomphalaria camerunensis populations

\begin{tabular}{|c|c|c|c|c|}
\hline Parameters & Snail species & $\mathrm{T}_{1}$ & $\mathrm{~T}_{2}$ & $p$-value \\
\hline \multirow[t]{2}{*}{ Number of $G_{1}$ individuals } & B. pfeifferi & 35 & 34 & \\
\hline & B. camerunensis & 30 & 30 & \\
\hline \multirow[t]{2}{*}{ Mean number of egg capsules (sd) } & B. pfeifferi & $19.0(4.1)$ & $19.3(3.7)$ & 0.732 \\
\hline & B. camerunensis & $18.9(12.6)$ & $27.9(11.9)$ & $0.010^{*}$ \\
\hline \multirow[t]{2}{*}{ Mean number of eggs (sd) } & B. pfeifferi & $363.2(66.0)$ & $366.6(72.9)$ & 0.840 \\
\hline & B. camerunensis & $121.2(95.8)$ & $315.2(183.8)$ & $<0.0001^{*}$ \\
\hline \multirow[t]{2}{*}{ Number of incubated capsules } & B. pfeifferi & 32 & 30 & \\
\hline & B. camerunensis & 36 & 42 & \\
\hline \multirow[t]{2}{*}{ Average incubation time (sd) } & B. pfeifferi & $9.6(0.5)$ & $9.4(0.8)$ & 0.202 \\
\hline & B. camerunensis & $10.0(1.7)$ & $8.2(0.9)$ & $<0.0001^{*}$ \\
\hline \multirow[t]{2}{*}{ Hatching rate $(95 \% \mathrm{Cl})$} & B. pfeifferi & $87.2(84.2-89.7)$ & $92.3(89.5-94.4)$ & 0.5323 \\
\hline & B. camerunensis & $68.8(63.6-73.5)$ & $92.3(89.9-94.3)$ & $<0.0049^{*}$ \\
\hline \multirow[t]{2}{*}{ Number of $G_{2}$ offspring } & B. pfeifferi & 30 & 30 & \\
\hline & B. camerunensis & 36 & 36 & \\
\hline \multirow[t]{2}{*}{$\mathrm{G}_{2}$ survival rate at $\mathrm{D}_{8}(95 \% \mathrm{Cl})$} & B. pfeifferi & $72.6(68.4-76.5)$ & $67.4(62.8-71.6)$ & 0.0848 \\
\hline & B. camerunensis & $94.3(90.5-96.6)$ & $82.5(78.8-85.7)$ & $0.0001^{*}$ \\
\hline \multirow[t]{2}{*}{$\mathrm{G}_{2}$ survival rate at $\mathrm{D}_{16}(95 \% \mathrm{Cl})$} & B. pfeifferi & $64.2(59.7-68.5)$ & $50.1(45.5-54.8)$ & $0.0001^{*}$ \\
\hline & B. camerunensis & $85.5(80.4-89.5)$ & $79.7(75.9-83.2)$ & 0.648 \\
\hline \multirow[t]{2}{*}{$\mathrm{G}_{2}$ survival rate at $\mathrm{D}_{30}(95 \% \mathrm{Cl})$} & B. pfeifferi & $54.1(49.5-58.6)$ & $39.2(34.8-43.9)$ & $0.0001^{*}$ \\
\hline & B. camerunensis & $82.5(77.0-86.9)$ & $76.7(72.7-80.3)$ & 0.0838 \\
\hline
\end{tabular}

sd: standard deviation; $95 \% \mathrm{Cl} 95 \%$ confidence interval; ${ }^{*}$ the difference is significant

camerunensis individuals (Table 2). For B. pfeifferi, the mean number of copulations was similar between the first and the second day of pairing $(p=0.064)$, but was significantly lower on the third day compared with the first two days of pairing $(p<0.0001)$. As for B. camerunensis, the mean number of copulations over the three days of pairing was similar between the first and the second day $(p=0.634)$, but significantly lower on the third day compared with the first two days of pairing $(p<0.006)$ (Table 2). Regarding the duration of copulations, a significant decreasing trend was observed between the first and the third day of pairing for B. pfeifferi $(p<0.0001)$ (Table 2). For B. camerunensis, the duration of copulations also gradually decreased during the three days of pairing, lasting about five hours the first day, and only fifteen minutes afterwards for most of the copulations. Although the mean number of copulations per individual and per day of pairing was significantly higher in B. pfeifferi compared with B. camerunensis (Table 2), the total duration of copulations over the three days of pairing was higher in $B$. camerunensis than in B. pfeifferi.

\section{Outcrossing estimates}

B. camerunensis egg production greatly increased within 6 days just after copulation before gradually decreasing, a maximum of 1,131 eggs being produced by paired individuals two days after copulation (Fig. 1; Table 1). No significant association was found between the number of copulations of paired B. camerunensis and both the number of egg capsules $(\mathrm{r}=0.225 ; p=0.233)$ and eggs $(\mathrm{r}=0.221 ; p=0.241)$. The mean number of egg capsules was significantly higher in $B$. camerunensis compared with $B$. pfeifferi $(p=0.001)$, whereas the mean number of eggs was similar between both species $(p=0.160)$. The offspring survival rate was, in general, higher in B. camerunensis than in $B$. pfeifferi, the survival slope revealing higher mortality on $D_{2}$, with subsequent decrease until $D_{12}$ before stabilizing on $\mathrm{D}_{16}$ (Fig. 2). A positive correlation was found between mortality and density of snails in the rearing boxes on D8 $(\mathrm{r}=0.625 ; p<0.0001)$, D14 $(\mathrm{r}=0.620 ; p<0.0001)$, and D30 ( $\mathrm{r}=0.719 ; p<0.0001)$.

\section{Comparison between the two treatments and inbreeding depression}

For B. pfeifferi, the number of egg capsules was not significantly different between inbred (mean: 19.0; sd: 4.1) and outbred (mean: 15.3; sd: 3.7) ( $p=0.732)$ individuals. A similar trend was observed for the mean number of eggs, with no significant difference between inbred (mean: 363.2; sd: 66.0) and outbred individuals (mean: 366.6; sd: 72.9) (Fig. 1). Incubation time and hatchability were similar between the two treatments (Table 1). Although survival rate was similar 
Table 2 Frequency and duration of copulations in Biomphalaria pfeifferi and Biomphalaria camerunensis populations

\begin{tabular}{|c|c|c|c|c|}
\hline Parameters & Snail species & No couples & Mean & sd of mean \\
\hline \multirow[t]{2}{*}{ Copulation frequency at first day of pairing } & B. pfeifferi & 15 & 1.9 & 0.7 \\
\hline & B. camerunensis & 15 & 1.9 & 0.7 \\
\hline \multirow[t]{2}{*}{ Copulation frequency at second day of pairing } & B. pfeifferi & 17 & 2.5 & 0.5 \\
\hline & B. camerunensis & 15 & 1.7 & 0.7 \\
\hline \multirow[t]{2}{*}{ Copulation frequency at third day of pairing } & B. pfeifferi & 17 & 1.2 & 0.7 \\
\hline & B. camerunensis & 15 & 1.0 & 0.7 \\
\hline \multirow[t]{2}{*}{ Copulation frequency over three days of pairing } & B. pfeifferi & 17 & 6.6 & 1.2 \\
\hline & B. camerunensis & 15 & 4.6 & 1.3 \\
\hline \multirow[t]{2}{*}{ Copulation duration at first day of pairing } & B. pfeifferi & 17 & 5.6 & 0.7 \\
\hline & B. camerunensis & 15 & 5.3 & 2.0 \\
\hline \multirow[t]{2}{*}{ Copulation duration at second day of pairing } & B. pfeifferi & 17 & 3.8 & 0.9 \\
\hline & B. camerunensis & 15 & 4.1 & 1.6 \\
\hline \multirow[t]{2}{*}{ Copulation duration at third day of pairing } & B. pfeifferi & 17 & 1.7 & 1.1 \\
\hline & B. camerunensis & 15 & 2.0 & 1.3 \\
\hline \multirow[t]{2}{*}{ Copulation duration over three days of pairing } & B. pfeifferi & 17 & 11.1 & 1.9 \\
\hline & B. camerunensis & 15 & 11.4 & 3.5 \\
\hline
\end{tabular}

No: number of; sd: standard deviation

between selfed and outcross offspring on $\mathrm{D}_{8}$ (Chi-square: 3.0; $p=0.08$ ), significant differences were found on $\mathrm{D}_{16}$ (Chi-square: 18.2; $p<0.0001$ ) and $\mathrm{D}_{30}$ (Chi-square: 19.81; $p<0.0001)$, inbred offspring having a better survival rate than their outbred counterparts.

For B. camerunensis, the number of egg capsules as well as the number of eggs laid was significantly lower in inbred than in outbred individuals $(p<0.01)$ (Table 1 ). The hatching rate of $G_{2}$ offspring was significantly higher in outbred eggs (92.3\%) compared with inbred eggs (68.8 \%) (Chi-square: $7.9 ; p=0.005)$. Also, these outbred eggs hatched faster than the inbred ones (Table 1). The survival rate of $G_{2}$ offspring from inbred
$G_{1}$ individuals, evaluated on $D_{8}$, was significantly higher than that of $G_{2}$ offspring from outbred $G_{1}$ (Chi-square: $18.0 ; p=0.0001$ ).

The self-fertilization (inbreeding) depression using the survival on $D_{0}$ (in such a way as to minimize the effect of density) and the survival on $\mathrm{D}_{30}$ was much higher in B. camerunensis ( $\mathrm{d}=0.71$ and $\mathrm{d}=0.53$, respectively) than in B. pfeifferi ( $\mathrm{d}=0.06$ and $\mathrm{d}=-0.26$, respectively).

\section{Discussion}

Rearing and natural living conditions of snails

The rearing conditions in the laboratory were slightly different from the natural living conditions of snails.
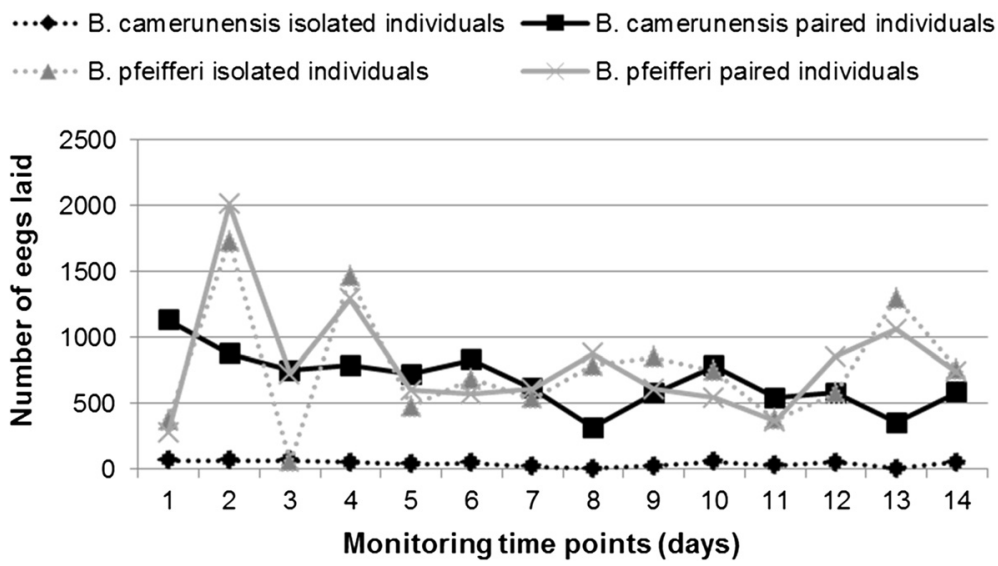

Fig. 1 Egg laying dynamics for isolated and paired individuals from Biomphalaria pfeifferi (grey lines) and Biomphalaria camerunensis (dark lines) populations. Dotted lines represent isolated individuals, and solid lines represent paired individuals 


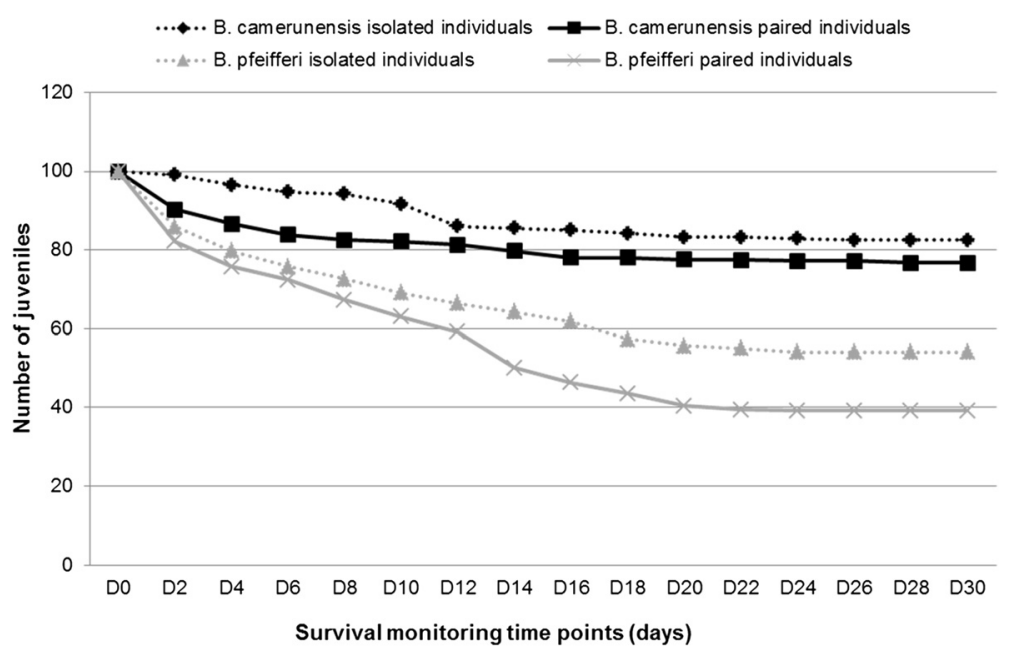

Fig. 2 Thirty-day survival trends in isolated and paired individuals from Biomphalaria pfeifferi (grey lines) and Biomphalaria camerunensis (dark lines) populations. Dotted lines represent isolated individuals, and solid lines represent paired individuals

Furthermore, these conditions, especially the $\mathrm{pH}$, seemed to be more favourable to $B$. pfeifferi than to $B$. camerunensis culture. However, numerous previous studies have shown that gastropod snails are tolerant to most water physicochemical parameters [30]; it was particularly demonstrated that the $\mathrm{pH}$ of water has little effect on mollusk populations, gastropods snails being able to tolerate all $\mathrm{pH}$ values, with a preference to standard values (between 6 and 9) [31].

\section{A plastic life-history trait: the age at sexual maturity} Reproduction of inbred individuals in B. pfeifferi population was initiated at about 63 days, later than previously reported in another Cameroonian population [28] but earlier than previously reported in Ivory Coast [20]. These differences in the age at sexual maturity can be explained by the large genetic differentiation among $B$. pfeifferi populations [17-19]. This finding is supported by the habitat openness (that reflects environmental stochasticity), the prevalence of the parasitic trematode $S$. mansoni and historical demography (colonization and subsequent bottlenecks). B. camerunensis individuals began laying eggs later than $B$. pfeifferi individuals, probably due to a delay resulting from a waiting time exhibited by isolated $B$. camerunensis individuals after reaching sexual maturity. Indeed, in preferential outcrossing species such as B. camerunensis, instead of laying bad eggs, isolated individuals tend to delay their reproduction to wait for the arrival of a mate [10]. This late egg-laying might lead to the overestimation of the age at sexual maturity for preferential outcrossing species. Also, the late age at first egg-laying in B. camerunensis allows the development of only 2 to 3 generations each year and may explain why the biology of this snail species is still less studied. On the contrary, the early age at first egg-laying exhibited by $B$. pfeifferi population might be considered as an advantageous feature for a fresh water snail population living in transient habitats.

\section{Copulatory activity}

Contrary to previous reports in high selfing populations like B. pfeifferi [20, 32], an important number of copulations was observed in our study. This could be explained either by differences in the experimental designs or by the high diversity of life history traits exhibited by $B$. pfeifferi populations [17-19]. In our study, individual snails were kept isolated during six weeks and paired after reaching sexual maturity, whereas in other experimental designs, individuals were isolated only two weeks prior to pairing, the latter starting before sexual maturity [20]. Virgin individuals, isolated since they hatched, might be eager to copulate as soon as they are paired as previously demonstrated either in selfing species like $B$. truncatus [33] or in outcrossing species like B. globosus $[34,35]$ and B. glabrata [36]. Despite a very low value of inbreeding depression in B. pfeifferi populations, copulations were observed in all pairs, indicating that copulation has no substantial influence on fecundity as has been previously shown in selfing species. Indeed, even when partners are available and copulation occurs, a large fraction of eggs from preferential selfing species self-fertilized [11] and only a small fraction of offspring then derive from outcrossing. Since previous studies using genetic markers had already demonstrated successful sperm transfer in Bulinus truncatus [33] and in Biomphalaria pfeifferi $[22,28]$, no genetic analysis was performed in the framework of our study. More investigations using molecular markers such as microsatellites would have been useful to assess the real fraction of individuals of this species that used foreign sperm. Also, 
the time and the number of copulations per day decreased over time as previously reported in B. forskalii, another preferential selfing species [13]. Once again, the experimental conditions can explain this observation.

Copulations were reported in all B. camerunensis pairs and the courtship behavior began within $30 \mathrm{~min}$ after pairing virgin individuals. These observations suggest that these individuals have a high propensity to copulate, a dominant mating system feature in outcrossing species [11]. In our study, the number of copulations was low than in B. glabrata [32] and in P. acuta [37], and might be explained by the design of our study. Also, no correlation was observed between the number of copulations and the fecundity, meaning that a single copulation may be enough to boost fecundity.

\section{Mating system parameters}

All isolated and virgin B. pfeifferi individuals started to lay eggs as soon as they reached sexual maturity. They also regularly produced egg capsules with fertile eggs, with a high hatching rate and subsequent survival. These observations demonstrate that B. pfeifferi individuals did not suffer from strong inbreeding, suggesting that selfing is the preferential mating system for this population. This was not surprising and confirms previous findings reporting the characterization of prior selfing (selfing initiated prior to any outcrossing) in B. pfeifferi [20]. In addition, no difference in fecundity (number of egg capsules and the number of eggs) was found between isolated and paired individuals, suggesting that pairing did not significantly affect the selfed mating system previously adopted by isolated individuals. Similar results have been observed in B. globosus from Ivory Coast, and B. forskalii from Cameroon $[9,13]$. It also appears that the presence of a mate partner does not significantly affect the development (incubation time) and the hatchability of eggs since both parameters were similar between the two treatments. However, the survival rate in $G_{2}$ offspring from selfing $G_{1}$ was significantly higher than in $G_{2}$ from outcrossed $G_{1}$. This result differed from that obtained in other B. pfeifferi populations where the survival rate of the selfing and the outcrossing groups were similar [20]. This might be explained by the higher hatching rate of $G_{1}$ egg capsules in outbred $(92.3 \%)$ than in inbred $(87.2 \%)$. As a consequence, a high offspring density was observed in boxes dedicated to outcrossing, and might explain the higher mortality rate observed. As expected, a limited inbreeding depression was observed in this study, indicating that selfing might be the preferential mating system in B. pfeifferi as previously suggested using isoenzymes [21]. In pulmonate snails, reproduction by selfing seems easy from a functional point of view. Both sperm and ovules are produced in a single reproductive organ, the ovotestis, and self-fertilization occurs within the hermaphroditic part of the reproductive tracts, while cross-fertilization requires copulation. Beyond this functional reason, the important reduction of the population size during some seasons can explain the selection of selfing as the preferential mating system.

Contrary to B. pfeifferi population, only $57.1 \%$ of $B$. camerunensis isolated individuals laid eggs before dying. Also, isolated individuals produced irregularly-shaped egg capsules containing few (or no) eggs. These egg capsules were smaller than those produced by the same snail after copulation. These observations suggest that these individuals markedly suffered from strong inbreeding, and indicate that this species prefers a biparental reproduction as was previously demonstrated in another obligate outcrosser Drepanotrema depressissimum [14]. Regarding the fecundity of these individuals, it appears that the mean numbers of egg capsules and eggs per snail were significantly higher in outbred than in inbred individuals. In cross fertile species L. peregra and Bulinus cernicus, no difference in egg capsules was found between the two treatments, but the mean number of egg (either per snail or per day) significantly increased after copulation [12, 38]. A positive correlation $(\mathrm{r}=0.830 ; p<0.0001)$ was found between the number of egg capsules and the number of eggs, meaning that a snail producing more egg capsules also lays more eggs after copulation. This high fecundity can be explained by the transfer of sperm as it was demonstrated in L. stagnalis [34]. In the course of our study, egg production greatly increased within a 6-day period just after copulation, and subsequently decreased. Similar trends were reported in B. globosus where isolated individuals switched to cross-fertilization less than 6 days after copulation, and were able to conserve the foreign semen for up to 11 days [9]. Since the foreign semen gradually decreased during three to five weeks after copulation, one can hypothesize that it was used for reproduction [36, 39, 40]. In spite of a higher hatchability in outcrossed egg capsules as compared to selfed egg capsules, no significant difference was found in the survival of $G_{2}$ juveniles. It was previously observed in other snail species (L. peregra and $D$. depressissimum) that survival rate in cross-fertilized juveniles was significantly higher than in the selfed ones. The high mortality rate in $G_{2}$ offspring deriving from outcrossing $G_{1}$ individuals might be explained by the high offspring densities in the rearing boxes. Indeed, an average of 13 individuals were observed in each box, whereas only six individuals were observed, on average, in each box containing $G_{2}$ offspring derived from selfing $G_{1}$ individuals. Another explanation might be the very short development of eggs in outcrossed egg capsules as a consequence of a short incubation time. As expected, our results indicated stronger differences 
between the selective values in self-fertilization than in cross-fertilization, with an inbreeding depression value lower than that obtained in L. peregra during the same time period (one month) [12]. On the contrary, this value was higher than the average apparent inbreeding depression displayed by B. glabrata, another preferential outcrosser species [11, 41]. It was hypothesized that the inbreeding depression in outcrossing populations is higher than one half $[2,42,43]$. Our results fit with this general prediction, and confirm that B. camerunensis is a preferential outcrosser species.

\section{Conclusions}

Although genetic markers were not used to ascertain that the eggs produced after pairings were the result of outcrossing and not a continuation of selfing, the present study tends to indicate, from phenotypical evidence, that the preferential mating system of B. pfeifferi is selfing. This result might explain why this species colonizes more diverse and inconstant habitats than $B$. camerunensis whose preferential mating system is outcrossing. In addition to that invasive ability, B. pfeifferi is suggested to be more compatible to $S$. mansoni than $B$. camerunensis, and then this mating system could favor the sustainability of $S$. mansoni life cycle where this intermediate host is present.

\section{Additional file}

Additional file 1: Study design. (TIF $120 \mathrm{~kb}$ )

\section{Abbreviations}

$\mathrm{G}_{0}$ : wild individuals; $\mathrm{G}_{1}$ : first generation; $\mathrm{G}_{2}$ : second generation; sd: standard deviation; 95 \% Cl: 95 \% confidence interval.

\section{Competing interests}

The authors declare that they have no competing interests.

\section{Authors' contributions}

ACKF collected field data, carried out laboratory experiments and drafted the manuscript. HCND performed the statistical analyses and helped to draft the manuscript. FFDT participated to the experiment design and helped to draft the manuscript. FN conceived and coordinated the study, designed the experiments and helped to draft the manuscript. All authors read and approved the final manuscript.

\section{Acknowledgements}

This study was funded by the Parasitology and Ecology Laboratory of the Faculty of Science of the University of Yaoundé 1; some laboratory equipment were provided by Mr. Fokam Eupolite. The authors are thankful to Doctor Philippe Jarne (Director of Research, CNRS, France) for his useful comments on the manuscript, and to Prof Paul Tan (Lecturer, University of Yaoundé 1, Cameroon) for language editing.

\section{Author details}

${ }^{1}$ University of Yaoundé 1, Parasitology and Ecology Laboratory, Faculty of Science, PO Box 812, Yaoundé, Cameroon. ${ }^{2}$ Centre for Research on Filariasis and other Tropical Diseases (CRFilMT), PO Box 5797, Yaoundé, Cameroon. ${ }^{3}$ Université des Montagnes, PO Box 208, Bangangté, Cameroon.
Received: 6 August 2015 Accepted: 25 December 2015

Published online: 06 January 2016

\section{References}

1. Jarne P, Auld JR. Animals mix it up too: the distribution of self-fertilization among hermaphroditic animals. Evolution. 2006;60:1816-24.

2. Jarne $P$, Charlesworth $D$. The evolution of the selfing rate in functionally hermaphrodite plants and animals. Annu Rev Ecol Evol Syst. 1993;24:441-66.

3. Jarne P, Vianey-Liaud M, Delay B. Selfing and outcrossing in hermaphrodite freshwater gastropods (Basommatophora): where, when and why. Biol J Linn Soc. 1993;49:99-125.

4. Jordaens K, Dillen L, Backeljau T. Effects of mating, breeding system and parasites on reproduction in hermaphrodites: Pulmonate gastropods (Mollusca). Anim Biol. 2007:57:137-95.

5. Schärer L. Tests of sex allocation theory in simultaneously hermaphroditic animals. Evolution. 2009;63:1377-405.

6. Jarne P, Pointier JP, David P, Koene JM. Basommatophoran Gastropods. In: Cordoba-Aguilar A, Leonard $J$, editors. The evolution of primary sexual characters in animals. New York: Oxford University Press; 2010. p. 173-96.

7. Dillon RT, McCullough TE, Earnhard CE. Estimates of natural allosperm storage capacity and self-fertilization rate in the hermaphroditic freshwater Pulmonate snail Physa acuta. Invertebrat Reprod Dev. 2005;47:111-5.

8. Vianey-Liaud M. Bias in the production of heterozygous pigmented embryos from successively mated Biomphalaria glabrata (Gastropoda: Planorbidae) albino snails. Malacol Rev. 1995;28:97-106.

9. Njiokou F, Bellec C, N'goran KE, Yapi-Yapi G, Delay B, Jarne P. Comparative fitness and reproductive isolation between two Bulinus globosus (Gastropoda: Planorbidae) populations. J Mollus Stud. 1992;58:367-76.

10. Tsitrone A, Jarne P, David P. Delayed selfing and resource reallocations in relation to mate availability in the freshwater snail Physa acuta. Am Nat. 2003;162:474-88.

11. Escobar SJ, Auld JR, Correa AC, Alonso AC, Bony YK, Coutellec M-A, et al. Patterns of mating-system evolution in hermaphroditic animals: correlations among selfing rate, inbreeding depression, and the timing of reproduction. Evolution. 2011:65(5):1233-53.

12. Jarne P, Delay B. Population genetics of Lymnaea peregra (Müller) (Gastropoda: Pulmonata) in the Lake Geneva. J Mollus Stud. 1990;56:317-21.

13. Njiokou F, Mouafo JB, Teukeng F, Njine T, Samè-Ekobo A, Jarne P. The influence of self-fertilization and pairing on life-history traits in the freshwater snail Bulinus forskalii (Gastropoda: Planorbidae). Acta Trop. 2000:76:159-67.

14. Lamy $T$, Levy L, Pointier JP, Jarne P, David P. Does life in unstable environments favour facultative selfing? A case study in the freshwater snail Drepanotrema depressissimum (Basommatophora: Planorbidae). Evol Ecol. 2012;26:639-55.

15. Woolhouse MEJ. Population biology of the freshwater snail Biomphalaria pfeifferi in the Zimbabwe highveld. J Appl Ecol. 1992;29:687-94.

16. Brown D. Fresh water snails of Africa and their medical importance. 2 nd ed. London: Taylor and Francis Ltd; 1994. p. 608.

17. Charbonnel N, Angers B, Rasatavonjizay R, Remond PB, Debain C, Jarne P. The influence of mating system, demography, parasites and colonization on the population structure of Biomphalaria pfeifferi in Madagascar. Mol Ecol. 2002;11:2213-28.

18. Charbonnel N, Angers B, Rasatavonjizay R, Remond PB, Debain C, Jarne P. Evolutionary aspects of the metapopulation dynamics of Biomphalaria pfeifferi, the intermediate host of Schistosoma mansoni. J Evol Biol. 2002;15:248-61.

19. Charbonnel N, Quesnoit M, Razatavonjizay R, Bremond P, Jarne P. A spatial and temporal approach to microevolutionary forces affecting population biology in the freshwater snail Biomphalaria pfeifferi. Am Nat. 2002;160:741-55.

20. Tian-Bi YN, N'Goran EK, N'Guetta SP, Matthys B, Sangare A, Jarne P. Prior selfing and the selfing syndrome in animals: an experimental approach in the freshwater snail Biomphalaria pfeifferi. Genet Res. 2008;90:61-72.

21. Mimpfoundi R, Greer GJ. Allozyme variation among populations of Biomphlaria pfeifferi (KRAUSS, 1848) (Gastropoda: Planorbidae) in Cameroon. J Mollus Stud. 1990;56:461-7.

22. Charbonnel N, Rasatavonjizay R, Sellin E, Bremond P, Jarne P. The influence of genetic factors and population dynamics on the mating system of the hermaphroditic snail Biomphalaria pfeifferi. Oikos. 2005;108:283-96. 
23. Greer GJ, Mimpfoundi R, Malek AE, Joky A, Ngonseu E, Ratard RC. Human schistosomiasis in cameroon. II. Distribution of the snail hosts. Am J Trop Med Hyg. 1990;42(6):573-80.

24. Mimpfoundi R, Greer GJ. Allozyme variation among populations of Biomphalaria camerunensis (Boettger, 1941) (Gastropoda: Planorbidae) in Cameroun. J Mollus Stud. 1990;56:373-81.

25. Coelho PMZ, Rosa FM, Maciel E, Negrão-Correa DA, Carvalho OS, Caldeira $\mathrm{RL}$, et al. Transmission control of schistosomiasis mansoni by introduction of a resistant strain of Biomphalaria tenagophila in areas where transmission is maintained by this species. Acta Trop. 2008;108:245-8.

26. Pointier JP, David P, Jarne P. The biological control of the snail hosts of schistosomes: the role of competitor snails and biological invasions. In: Toledo R, Fried B, editors. Biomphalaria snails and larval trematodes. New York: Springer; 2011. p. 215-38.

27. Goodwillie C, Knight MC. Inbreeding depression and mixed mating in Leptosiphon jepsonii: A comparison of three populations. Ann Bot. 2006:98:351-60.

28. Etang JD. Etudes systématiques, génétiques et biologiques dans la malacofaune des étangs de Mbalmayo. Yaoundé, Cameroun: Mémoire de maîtrise, Université de Yaoundé l; 1996.

29. Escobar JS, Nicot A, David P. The different sources of variation in inbreeding depression, heterosis and outbreeding depression in a metapopulation of Physa acuta. Genetics. 2008;180:1593-608.

30. Hussein MA, Obuid-Allah AH, Mahmoud AA, Fangary HM. Population dynamics of freshwater snails (Mollusca: Gastropoda) at Qena Governorate, Upper Egypt. Egypt Acad J Biolog Sci. 2011;3(1):11-22.

31. Yapi Yapi G, Toure M, Boka Ohoukou M, Tia E, Boby Ouassa AM, Kadjo KA. Dynamique des populations de Biomphalaria pfeifferi et de Bulinus globosus en zone d'endémie schistosomienne en Côte d'Ivoire. Europ Sci J. 2014;10:339-63.

32. Rupp JC, Woolhouse MEJ. Impact of geographical origin on mating behaviour in two species of Biomphalaria (Planorbidae: Gastropoda). Anim Behav. 1999:58:1247-51.

33. Njiokou F, Bellec C, Jarne P, Finot L, Delay B. Mating system analysis using electrophoresis in the self-fertile hermaphrodite species Bulinus truncatus (Gastropoda: Planorbidae). J Mollus Stud. 1992;59:125-33.

34. Van Duivenboden YA. Transfer of semen accelerates the onset of egg-laying in female copulants of the hermaphrodite freshwater snail, Lymnaea stagnalis. Int J Invert Reprod. 1983;6:249-57.

35. Rudolph PH. Copulatory activity and sperm production in Bulinus (Physopsys) globosus (Gastropoda: Planorbidae). J Mollus Stud. 1983;49:125-32.

36. Vianey-Liaud M. Sperm storage time in Biomphalaria glabrata (Gastropoda: Planorbidae): fertilization of albino snails by surgically castrated pigmented snails. J Med Appl Malacol. 1992;4:99-101.

37. Facon B, Ravigne V, Goudet J. Experimental evidence of inbreeding avoidance in the hermaphrodite snail Physa acuta. Evol Ecol. 2006;20:395-406

38. Rollinson KRA, Lines JRL. An analysis of fertilization in Bulinus cernicus (Gastropoda: Planorbidae). Zoology. 2009:217(2):295-310.

39. Njiokou F. Génétique et biologie des populations de deux hôtes intermédiaires de schistosomes à œuf à éperon terminal: Bulinus globosus (Morelet, 1866) et B. truncatus (Audouin, 1827); conséquences épidémiologiques. Thèse de Doctorat, Université de Montpellier II, Montpellier, France;1992.

40. Vianey-Liaud M. La reproduction chez un Mollusque hermaphrodite simultané : le planorbe Biomphalaria glabrata (Say, 1818) (Gastéropode, Pulmoné). Haliotis. 1997;27:67-114.

41. Costa MJFS, Grault CE, Confalonieri UEC. Comparative study of the fecundity and fertility of Biomphalaria glabrata (Say, 1818) and Biomphalaria straminea (Dunker, 1848) in a laboratory through self-fertilization and cross-fertilization. Rev Inst Med Trop Sao Paulo. 1818;2004(46):157-63.

42. Uyenoyama $\mathrm{M}$, Holsinger $\mathrm{KE}$, Waller D. Ecological and genetic factors directing the evolution of self-fertilization. Oxford Surv Evol Biol. 1993;9:327-81.

43. Husband B, Schemske D. Evolution of the magnitude and timing of inbreeding depression in plants. Evolution. 1996;50:54-70.

\section{Submit your next manuscript to BioMed Central and we will help you at every step:}

- We accept pre-submission inquiries

- Our selector tool helps you to find the most relevant journal

- We provide round the clock customer support

- Convenient online submission

- Thorough peer review

- Inclusion in PubMed and all major indexing services

- Maximum visibility for your research

Submit your manuscript at www.biomedcentral.com/submit
Biomed Central 